\title{
Taguchi Optimization for Waste Cooking Oil Based Biodiesel Preparation
}

\author{
Pravinkumar D. Patil, Aditya M. Buradkar, Masoomraja Zakir Mulla, P. A. Prabhu, J. R. Nagla
}

\begin{abstract}
Biodiesel is a promising future fuel. In the recent times lots of research has been done to make the waste product as a valuable product. The option which best suits is the biodiesel which can be obtained from Waste cooking oil using Various methods. The prominenet technique is the one which gives best results with the addition of less parameters involved in it. Biodiesel is acquired from edible, non-edible vegetable oils and animal fats as well. Well, a known route to manufacture biodiesel is trans-esterification of acylglycerol that undergo catalyzed esterification with methanol. With an aid of a suitable experimental design, it is vital to optimize various parameters that affect product yield and quality. A novelty of our work lies in implementing Taguchi Design for process optimization. The analysis gives an optimized set of process parameters namely oil to alcohol molar ratio as $1: 7$, catalyst congregation as $1 \%$, latency as $20 \mathrm{~min}$ as well as intense heat as $50^{\circ} \mathrm{C}$. using these optimum conditions, the biodiesel prepared is found to have the highest yield of $75.18 \%$, moreover diesel quality is also acceptable as per ASTM criteria. Its environmental benefits and renewability attract both industry and academia for further research.
\end{abstract}

Keywords: Trans-esterification, Waste Cooking Oil Biodiesel, Yield, Taguchi, ANOVA.

\section{INTRODUCTION}

In the current energy scenario, biodiesel as a potential substitute to diesel fuel has become vital because of two advantages namely its ecological sake as well as reality that it arise from renewable resources. However, its long term suitability, engine characteristics and the cost of production are the main hurdles for commercialization of the product [5]. Biodiesel as such is prepared from triglycerides of drippings or ruminant fats. Esters of methyl are separated from glycerin by catalyzed reaction of methanol with triglycerides. It has been found that vegetable oils hold special promise in this regard. It is due to the reason that these oils are obtained from the plants buildup in hinterland. Drippings from crops such as soya bean, peanut, sunflower, rape, coconut, karanja, neem, cotton, mustard, jatropha, linseed and caster have been evaluated around the globe in contrast with further contaminated oils for producing biodiesel [12].

Revised Manuscript Received on February 21, 2020.

* Correspondence Author

Dr. Pravinkumar D. Patil*, Assistant Professor, Department of Chemical Technology, Shivaji University, Kolhapur, India.

Mr. Aditya M. Buradkar, Faculty, Department of Process and systems Engineering, Otto-Von-Guericke University, Magdeburg, Germany.

Mr. Masoomraja Zakir Mulla, Student, Department of Technology, Shivaji University, Kolhapur, India.

Mr. P. A. Prabhu, Assistant Professor, Department of Mechanical Engineering, Shivaji University, Kolhapur, India.

Prof. J. R. Nagla, Statistician, Department of Statistics, Textile and Engineering, Institute, Ichalkaranji, India.

(C) The Authors. Published by Blue Eyes Intelligence Engineering and Sciences Publication (BEIESP). This is an open access article under the CC BY-NC-ND license (http://creativecommons.org/licenses/by-nc-nd/4.0/)
Waste cooking oil is much cheap than comparison with pure drippings, is a optimistic substitute to dripping for production of biodiesel $[9,13]$. The feedstock collected from waste or used drippings is frequently called as waste cooking oils (WCO). It is one of the alternative sources in contrast with purified oils. Gathering of waste cooking oil is simple from different industries like captive use, hotels also the restaurants. WCOs being cheaper than other fresh or refined oils, we can reduce the cost of biodiesel production. Using these waste oils for biodiesel production also prevents environment pollution. These oils need treatment prior to their disposal to the environment to prevent pollution. Many reckless proprietors, due to the high treatment cost, dispose of these WCOs directly to the environment. The use of WCOs is an effective method for making biodiesel production cheap as well as it will reduce nuisance to the environment [14].

[4] Claim that these WCOs can be an important source for biodiesel production as there is large quantity of WCOs available from hotels and factories. Use of WCOs helps improvement of the biodiesel economics. [1] explained utilization of WCOs plays an importanat role in optimising biodiesel production fetch upto 60-70\%. Although, the cooking process has dismissive effect on oil characteristics and can develop various types of adulteration in the oil. It might also multiply the Free Fatty Acid and water composition of oil. Trans-esterification reaction is the prime method for manufacturing and development of biodiesel. Various paths like Acid, alkali or enzymatic catalyzed and non-catalytic trans-esterification have been already tried for biodiesel manufacturing.

Thorough review of literature sheds light on various alternative fuels, various feed stocks of biodiesel, seed estimation, oil estimations, standards used for suitability of biodiesel, etc. Among various techniques of biodiesel preparation, trans-esterification is reported as crucial one. Also, various researches have been carried out for catalyst such as solid alkali, acid, enzymatic etc. Further, few researchers have studied effect of alcohol (methanol, ethanol and butanol). Very few researchers have worked on optimization of process variables like reaction time, reaction temperature, two step or one step reaction for increasing yield or quality. Various review papers on preparation of biodiesel with WCO have been studied. It focuses on low cost of raw oil. Also, minimizes problem of disposal of WCO to environment. Further, various results of fuel properties and engine test result have created interest for keen study for laboratory scale WCO biodiesel preparation. Now, it is very important to optimize various variables such as molar ratio, catalyst concentrations, latency and intense heat. 
We decided to adopt Taguchi approach, a robust design for the purpose of optimization in the preparation of laboratory scale biodiesel from WCO. ANOVA results are used to arrive at the optimized set of selected parameters. Further the biodiesel obtained using optimum levels of process parameters, has been tested so as to check its suitability as a fuel [15].

\section{MATERIALS AND METHODS}

\section{A. Taguchi Approach for Optimization of Parameters}

The strategy of spreading out the plans of trial circumstances including various parameters was first done in 1920 by Sir R.A. Fisher called full factorial structure. In this system every single imaginable blend of parametric qualities are considered however most modern investigations include critical number of components so full factorial structure brings about huge number of trials. For instance, in an exploratory structure having seven parameters, each at two levels, all out number of analyses would be 27 for example 128. To decrease the quantity of trials just a little arrangement of potential blends is chosen. This strategy is called incomplete factorial structure and creates most data however there are no broad rules for the utilization of this system. Taguchi's methodology viewed as both significant territories by plainly characterizing a lot of symmetrical exhibits to structure the trials and by conceiving a standard technique to dissect the outcomes got. Plan of investigations by symmetrical exhibits offers extraordinary test productivity [2].

\section{Design of experiment (DOE) used in the process optimization.}

Taguchi has built up symmetrical clusters to portray huge number of trial circumstances. Symmetrical clusters are a lot of tables of numbers which can be utilized to proficiently achieve ideal structure. The representative assignment of the exhibit conveys the data on the size of the examinations. For instance a L8 exhibit demonstrates that 8 preliminaries are required [2].

Each symmetrical cluster must fulfill adjusting property. As indicated by adjusting property the associations between two degrees of elements in exploratory structure must be happened equivalent number of times. For instance if association between level 1 and level 2 of two distinct variables happens thrice then the connections between level 2 and level 1 of these elements must happen thrice. Determination of an appropriate symmetrical cluster is must to achieve the exact outcomes. To choose appropriate symmetrical exhibit first :

Degree of freedom is determined by the accompanying condition:

degree of freedom $=p(l-1)$

Where $\mathrm{p}=$ number of parameters

$$
\mathrm{l}=\text { number of levels }
$$

For instance in above case there are four parameters and three quantities of levels so level of opportunity gets 8. Presently we should perform least eight investigations to accomplish the require results. This should be possible by choosing a L9 cluster. However, to keep away from the mistake one should utilize Taguchi's exhibit selector to choose the reasonable cluster and the tests must be structured by the predefined symmetrical exhibits. Consider a case of biodiesel generation yield in which there are four parametric varieties to be specific liquor to oil molar proportion, impetus type with its fixation and response time and temperature. These are found have critical effect on the creation yield. We proposed to change all these four parameters each at three levels [2]. The controlling parameters and their levels are appeared in table 1 [16].

Table-I : Chosen Process parameters and their level

\begin{tabular}{|c|c|c|c|c|}
\hline \multirow{2}{*}{ Sr. No. } & \multirow{2}{*}{$\begin{array}{c}\text { Control } \\
\text { Process } \\
\text { parameters }\end{array}$} & 1 & 2 & 3 \\
\cline { 3 - 5 } A & $\begin{array}{c}\text { Methanol to } \\
\text { Oil Molar } \\
\text { ratio }\end{array}$ & $5: 01$ & $7: 01$ & $9: 01$ \\
\hline \multirow{2}{*}{ B } & $\begin{array}{c}\text { Catalyst } \\
\text { concentration }\end{array}$ & 0.5 & 1 & 1.5 \\
\cline { 2 - 4 } C $\begin{array}{c}\text { (\% wt.) } \\
\text { C }\end{array}$ & $\begin{array}{c}\text { Reaction } \\
\text { time (min) }\end{array}$ & 10 & 20 & 30 \\
\hline D & $\begin{array}{c}\text { Reaction } \\
\text { temperature } \\
\left({ }^{0} \mathrm{C}\right)\end{array}$ & 50 & 60 & 70 \\
\hline
\end{tabular}

\section{Selection of control parameters and their levels}

Among the various parameters affecting the generation yield of biodiesel, for example,

response temperature, time for response, kind

of liquor and its amount, kind of impetus and its fixation, fomentation or mixing speed, nature of the reactants and dampness content in the oil, just the four most impacting parameters and three levels $(\mathrm{L}=3, \mathrm{P}=4$ as appeared in Table. 1 have been considered in this investigation. The impacts of the four picked parameters at three distinct levels have been contemplated by leading just nine examinations according to L9 OA Shown in Table 2.

Each investigation has been rehashed thrice so as to limit the mistakes. The percentage yield as a measure of quantity produced was considered as the response variable for the experiment [17].

For the above example control parameters as stated in table 1 , and average \% yield is shown in table 2 [16]. 
Table-II : L9 Orthogonal array for Design of Experiment

\begin{tabular}{|c|c|c|c|c|c|c|c|c|}
\hline \multirow[t]{2}{*}{ Sr no. } & \multicolumn{4}{|c|}{ Parameters } & \multicolumn{3}{|c|}{ Percentage of yield } & \multirow{2}{*}{$\begin{array}{l}\text { Mean Yield } \\
\text { Percentage }\end{array}$} \\
\hline & A & B & $\mathrm{C}$ & D & Trial1 & Trial2 & Trial3 & \\
\hline 1 & 5:01 & 0.5 & 10 & 50 & 66.66 & 61.6 & 70.69 & 66.31 \\
\hline 2 & 5:01 & 1 & 20 & 60 & 67.74 & 70.96 & 64.51 & 67.73 \\
\hline 3 & 5:01 & 1.5 & 30 & 70 & 51.61 & 58.06 & 66.12 & 58.59 \\
\hline 4 & 7:01 & 0.5 & 20 & 70 & 67.74 & 64.51 & 80.64 & 70.96 \\
\hline 5 & 7:01 & 1 & 30 & 50 & 67.16 & 74.62 & 67.16 & 69.64 \\
\hline 6 & 7:01 & 1.5 & 10 & 60 & 67.74 & 64.51 & 67.74 & 66.67 \\
\hline 7 & 9:01 & 0.5 & 30 & 60 & 51.61 & 61.29 & 48.38 & 53.76 \\
\hline 8 & 9:01 & 1 & 10 & 70 & 67.74 & 67.74 & 50 & 61.82 \\
\hline 9 & 9:01 & 1.5 & 20 & 50 & 69.44 & 59.15 & 59.15 & 62.58 \\
\hline
\end{tabular}

\section{Statistical Analysis of data in optimization of WCO trans-esterification to yield biodiesel}

Utilizing Minitab programming rendition 13, investigation was led for the reaction variable (rate yield). The General Linear Model (GLM) approach was utilized to perform investigation of fluctuation and relapse of the reaction variable. Counts were performed utilizing a relapse approach. Ends were drawn utilizing determined outcomes and the diagrams [11]. The ANOVA for percent yield was acquired from the product (Table 3 ) [17].
The statistical analysis showed that only molar ratio significantly affects the percent yield. Further the mean values of percent yield as 64, 69, and 59 for levels of molar ratios 1, 2 and 3 respectively. For catalyst concentration with the levels 1, 2 and 3, the mean percent yield values are 63.5, 66.2 , and 62.5 individually. The three degrees of time of response show the mean estimations of percent yield as 64.5, 66.5, and 60.5 separately. At long last for the response temperature as a parameter, for the three separate levels, the mean percent yield esteems anticipated are 66, 61, and 64 individually.

Table-III: ANOVA results

\begin{tabular}{|c|c|c|c|c|c|}
\hline Source & DF & Adj SS & Adj MS & F-Value & P - Value \\
\hline Molar Ratio & 2 & 423.6 & 211.801 & 4.68 & 0.025 \\
\hline Catalyst & 2 & 68.76 & 34.378 & 0.76 & 0.484 \\
\hline Time & 2 & 192.47 & 96.237 & 2.12 & 0.152 \\
\hline Temp. & 2 & 56.48 & 28.204 & 0.62 & 0.549 \\
\hline Trial & 2 & 3.67 & 1.835 & 0.04 & 0.96 \\
\hline Error & 16 & 724.72 & 45.295 & & \\
\hline Total & 26 & 1496.7 & \multicolumn{3}{l}{} \\
\hline
\end{tabular}

\section{B.Preparation and Testing Of Biodiesel.}

As waste cooking oil from cotton seed oil is promptly accessible and has significant unsaturated gatherings, it is a reasonable and less expensive crude material for biodiesel generation. Biodiesel is produced in two stages involving esterification and trans-esterification processes. After reaction completion, two distinct layers formed are separated using a funnel for the purpose. Washing is then done to create the nonpartisan biodiesel further to catalyze glycerol, cleanser and methanol.

\section{Feedstock of Waste Cooking Oil.}

The generation of waste cooking oil will be the capacity of the browning temperature and length of utilization just as the material utilized for searing. It is obtained from domestic, commercials (hotels) and industrial sources of used or waste cooking oil after frying foods. In present work WCO used is from cottonseed oil. It is so because India is second largest country in world for cotton seed oil production and consumption [14].

\section{Free Fatty Acids}

For FFA under 2\%, it might legitimately be taken for trans-esterification process while in the event of FFA (Free Fatty Acid) over $2 \%$, it needs to begin from esterification procedure to diminish FFA. 
The corrosive estimation of the waste cooking oil was resolved so as to appraise the free unsaturated fat substance and to get a thought of how a lot of corrosive impetus and methanol would be expected to drive the corrosive esterification compound towards methyl ester creation. It was suggested that $0.5-1.5 \%$ (in view of the heaviness of free unsaturated fat in the oil) of unadulterated (95-98\%) sulphuric corrosive ought to be utilized as an impetus [14]. Corrosive worth is found by titration technique. Different materials like $\mathrm{KOH}$ (potassium hydroxide), and methanol were utilized in methyl ester change response.

\section{Molecular weight of Waste cooking Oil}

Atomic load of waste cooking oil can be determined from the corrosive worth (National Standard of China, GB 5530-85) and saponification esteem (GB 5530-85) of WCO [22].

The normal sub-atomic load of WCO is determined by :

$\mathrm{M}=56.1 \times 1000 \times 3 /(\mathrm{SV}-\mathrm{AV})$

Where,

$\mathrm{AV}$ is the corrosive worth (m KOH/m oil, $\mathrm{mg} / \mathrm{g}$ ) and $\mathrm{SV}$ is the saponification esteem ( $\mathrm{m} \mathrm{KOH} / \mathrm{m}$ oil, $\mathrm{mg} / \mathrm{g}$ ).

Where, Acid and Saponification estimation of WCO is 1.7 and $198.35 \mathrm{mg} / \mathrm{g}$ Resp.

Different advances pursued for biodiesel creation from squander cooking oil are depicted as following:

For methyl ester change squander cooking oil test $(100 \mathrm{ml})$ was first preheated to $50^{\circ} \mathrm{C}$. Methanol (by volume) and strong impetus (by weight) were blended and mixed in a different funnel shaped flagon.

After that the blended example was included preheated squander cooking oil test.

A batch reactor drenched in a water shower, able to keep up ( \pm 10C) required response temperature, was utilized for trans-esterification. To blend the reactants appropriately a consistent shaker, which changes over the electric force into mechanical shaking, was utilized at impeller running at 300 rpm. This was accomplished for various response times (10, 20 and 30 minutes) for required examples.
After trans-esterification the example was taken in an isolating pipe having a waste valve. The blend was made to make due with twenty four hours and afterward the glycerol was isolated. Excess methanol and contaminations were expelled by washing the methyl ester with refined water at $40^{\circ} \mathrm{C}$.

All of the above advances were rehashed for various estimations of parameters controlling creation yield, for example, unique molar proportions (5:1, 7:1, 9:1), distinctive response times (10,20 and 30 minutes), diverse response temperatures $\left(50,60\right.$ and $\left.70^{\circ} \mathrm{C}\right)$ and utilizing various impetuses at various fixations (0.5,1.0 and 1.5 by weight\%) of impetus. Figure 2 is shows glycerol detachment from methyl ester by utilizing isolating channel [14,16,18,21].

\section{Esterification}

Esterification is one of steps in biodiesel generation. It attempts to diminish FFA if FFA is over $2 \%$. As given sample of waste cooking ottonseed oil has FFA less than 2\%, direct trans-esterification process has been carried out [14]

\section{Trans-esterification}

Trans-esterification process works so as to reduce viscosity of the biodiesel. In our case, FFA (Free Fatty Acid) was less than $2 \%$ so we conducted the

trans-esterification step directly. Potassium hydroxide was utilized as impetus in this procedure.

The measure of impetus had an effect in the change of esters during the trans-esterification process. The response was completed utilizing $1 \%$ of impetus focus. Before trans-esterification process, Potassium hydroxide was first combined with methanol in one compartment before adding to the waste cooking oil. In the wake of including the methanol/Potassium hydroxide and waste cooking oil the instigator was utilized to blend the solvents until they got cloudy. This was then warmed to about $50^{\circ} \mathrm{C}$ for 20 minutes as appeared in fig. 1 [14].

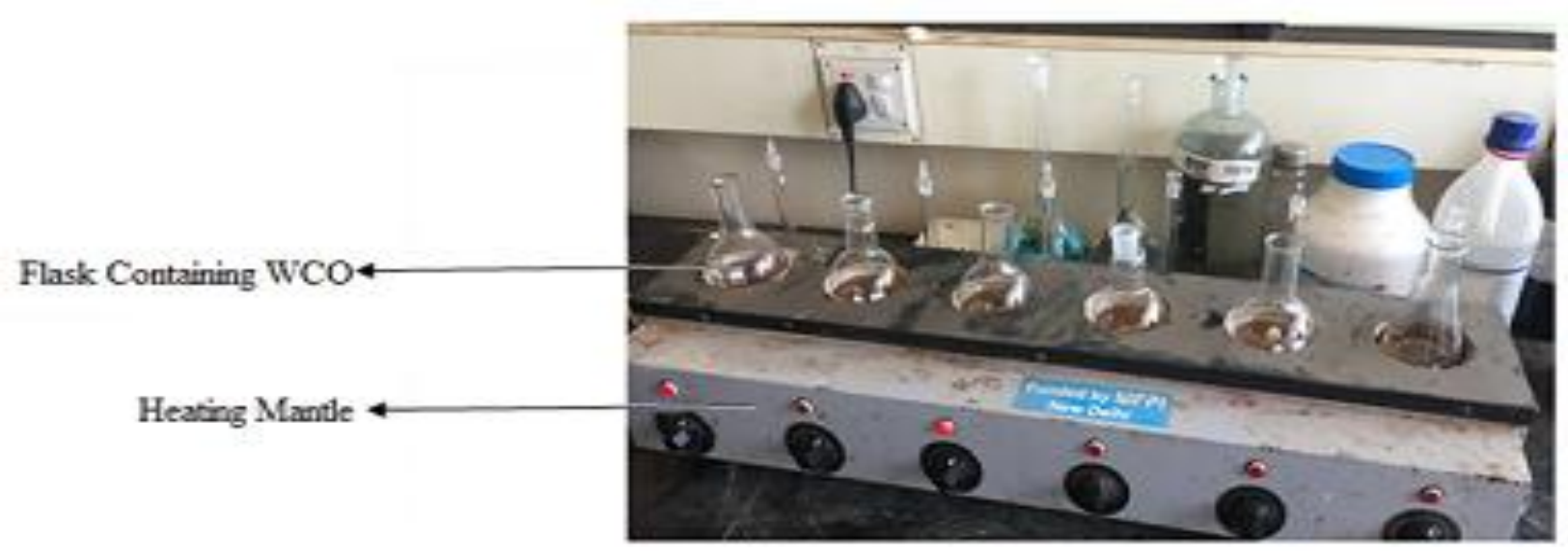

Fig. 1 .Trans-esterification process 


\section{Product Separation}

After the trans-esterification process, the resultant biodiesel was left to lie for at any rate 8 hours. Isolating pipe was utilized to isolate the top (methyl ester) and base (glycerol) layers. Two layers could unmistakably be found in the effective fundamental trans-esterification biodiesel tests. The top layer was predominantly made out of free unsaturated fat methyl esters. The base store was for the most part comprised of glycerol, salts, cleanser, different pollutions and abundance methanol as it is an extremely polar compound for example it segments more with polar glycerol instead of the non-polar methyl esters as appeared in fig. 2 [14]

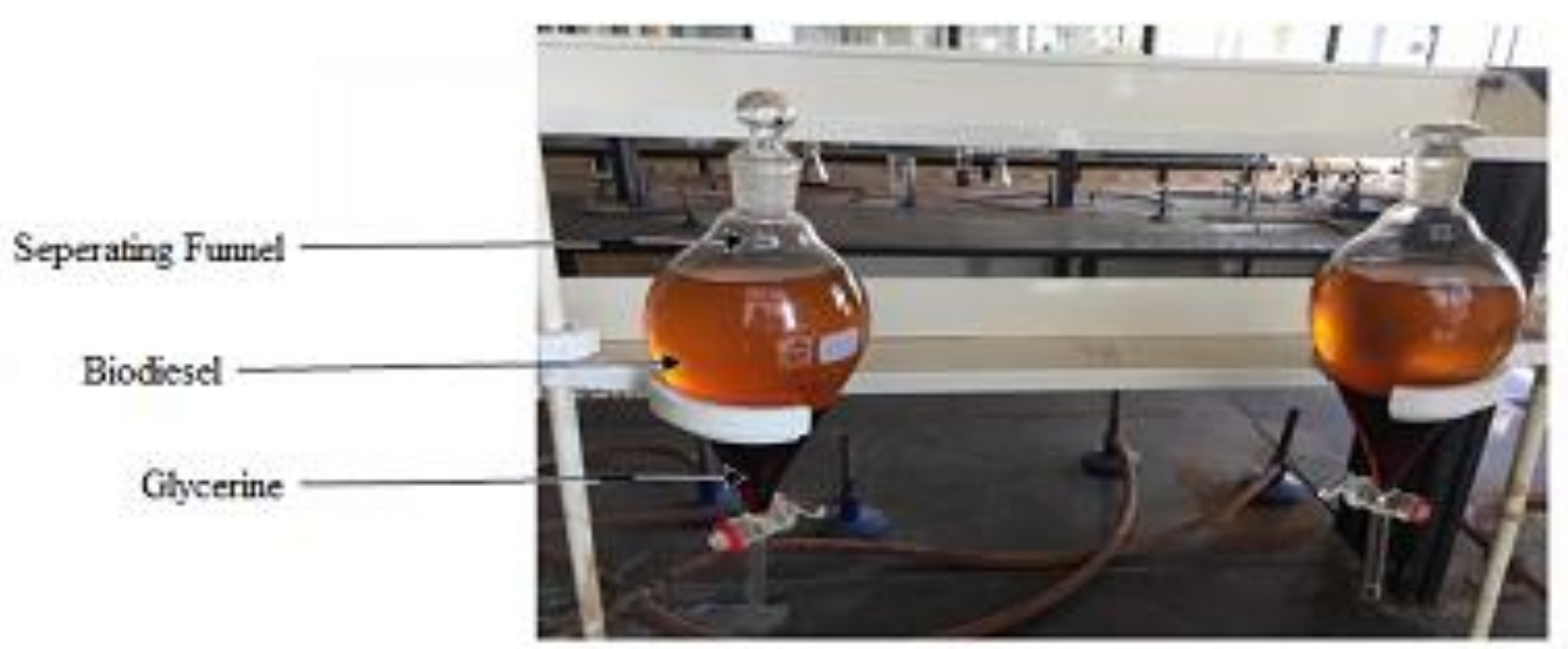

Fig. 2.Separation of FAME and glycerine

\section{Washing}

The top methyl ester layer was isolated and evacuated. The water washing process was pursued for the biodiesel. When isolated from the glycerine, the biodiesel is at times refined by washing tenderly with warm water to evacuate leftover impetus or cleansers, dried, and sent to capacity. In certain procedures this progression is superfluous. This is typically the finish of the generation procedure bringing about an unmistakable golden yellow fluid

with a consistency like petro diesel. In certain frameworks the biodiesel is refined in an extra advance to expel limited quantities of shading bodies

to deliver a vapid biodiesel as appeared in fig. 3 [14, 21].

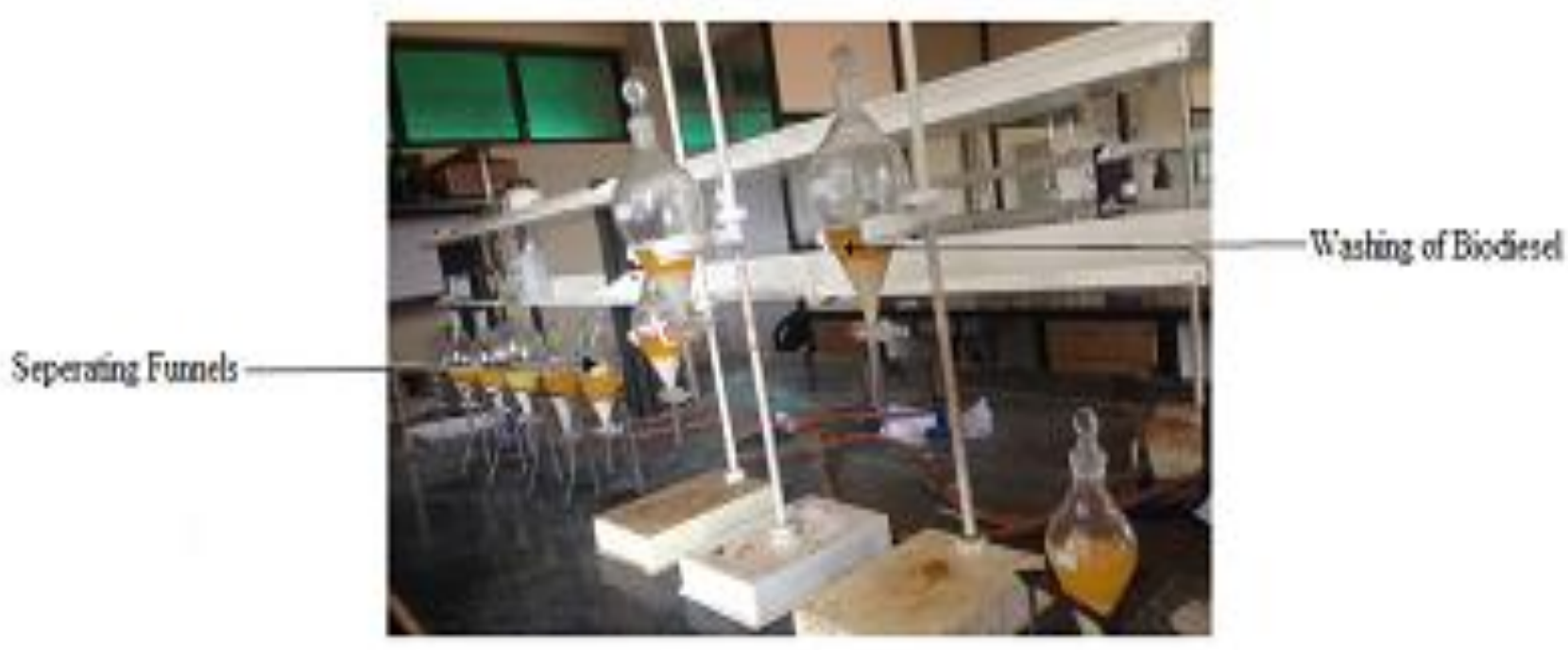

Fig. 3.Washing and distillation process

Published By: 


\section{Drying}

In the wake of washing water still have inside biodiesel. Along these lines the water must be expelled from the biodiesel utilizing drying at $120^{\circ} \mathrm{C}$ for 24 hour as appeared in fig. 4

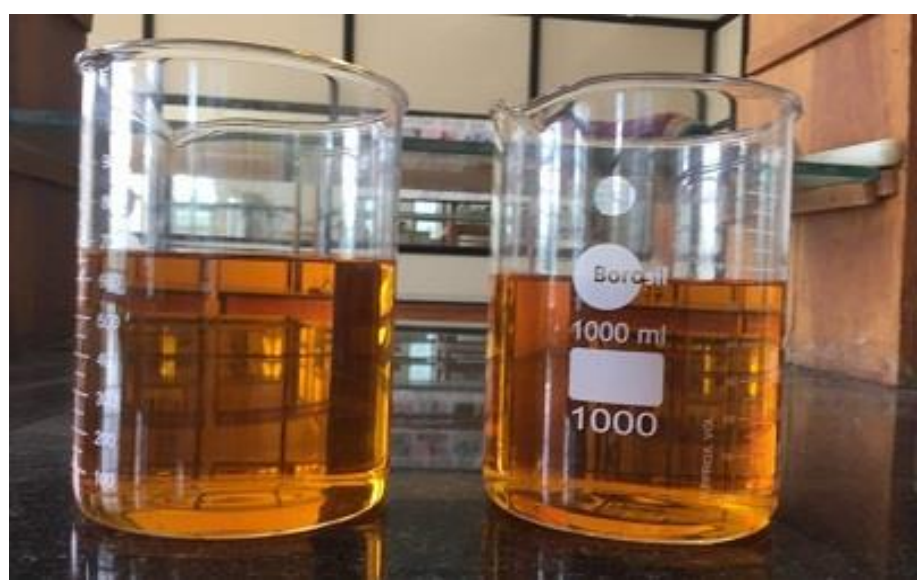

Fig. 4.Biodiesel after drying

\section{Properties of Biodiesel}

The benefits of Biodiesel over Diesel fuel are higher ignition proficiency, higher cetane number and higher biodegradability and less carbon monoxide discharges. Anyway with the natural points of interest of biodiesel, the weaknesses of utilizing Biodiesel merit referencing. These incorporate somewhat higher $\mathrm{NOx}$ (nitrogen oxide) emanations, cold beginning issues, lower vitality content, higher copper strip consumption and fuel siphoning trouble coming about because of higher consistency. As of now, biodiesel is costly to create than diesel, which gives off an impression of being the essential factor in averting its increasingly across the board use.
There are different thermodynamic and physical properties of feed oils which are very significant for the procedure displaying and recreation instruments.

Thermo-physical properties of biodiesel are utilized for the portrayal of biodiesel and they are additionally required for the burning displaying [7,10,12] Physical properties of biodiesel and their qualities or range are given in the table 4 [16].

Table-IV : Physical Properties of Biodiesel

\begin{tabular}{|c|c|c|c|c|}
\hline & Properties & Unit & $\begin{array}{l}\text { Diesel } \\
\text { (ASTM D975) }\end{array}$ & $\begin{array}{l}\text { WCO } \\
\text { Biodiesel } \\
\text { (ASTM PS 121) }\end{array}$ \\
\hline \multicolumn{5}{|c|}{ Chemical Properties } \\
\hline 1 & Acid Value & $\mathrm{mg} \mathrm{KOH/g}$ & 0.11 & 0.44 \\
\hline 2 & Cetane number & - & 46 & 52 \\
\hline 3 & Water content & $\mathrm{mg} / \mathrm{kg}$ & $<200$ & 320 \\
\hline \multicolumn{5}{|c|}{ Physical Properties } \\
\hline 4 & Density & $\mathrm{g} / \mathrm{cm}^{3}$ & 0.8 & 0.868 \\
\hline 5 & Viscosity & $\mathrm{mm}^{2} / \mathrm{s}$ & 2.5 & 3.58 \\
\hline 6 & Flash point & ${ }^{0} \mathrm{C}$ & $>55$ & 135 \\
\hline 7 & Fire point & ${ }^{0} \mathrm{C}$ & 60 & 141 \\
\hline 8 & Calorific value & $\mathrm{KJ} / \mathrm{kg}$ & 42,000 & 37531 \\
\hline
\end{tabular}




\section{RESULTS AND DISCUSSION}

\section{A. Optimization experiment}

Difference investigation results demonstrated measurable hugeness of picked conditions. The F-esteem for every parameter demonstrates which parameter has critical impact on item yield and is essentially a proportion of the squared deviation to the mean of squared blunder. Typically, bigger F-esteem shows more noteworthy impact on the yield because of the difference in the process parameter. Ideal blend of procedure parameters was anticipated utilizing ANOVA as appeared in Figure 5 [16]

Figure 5: Factorial effect graphs

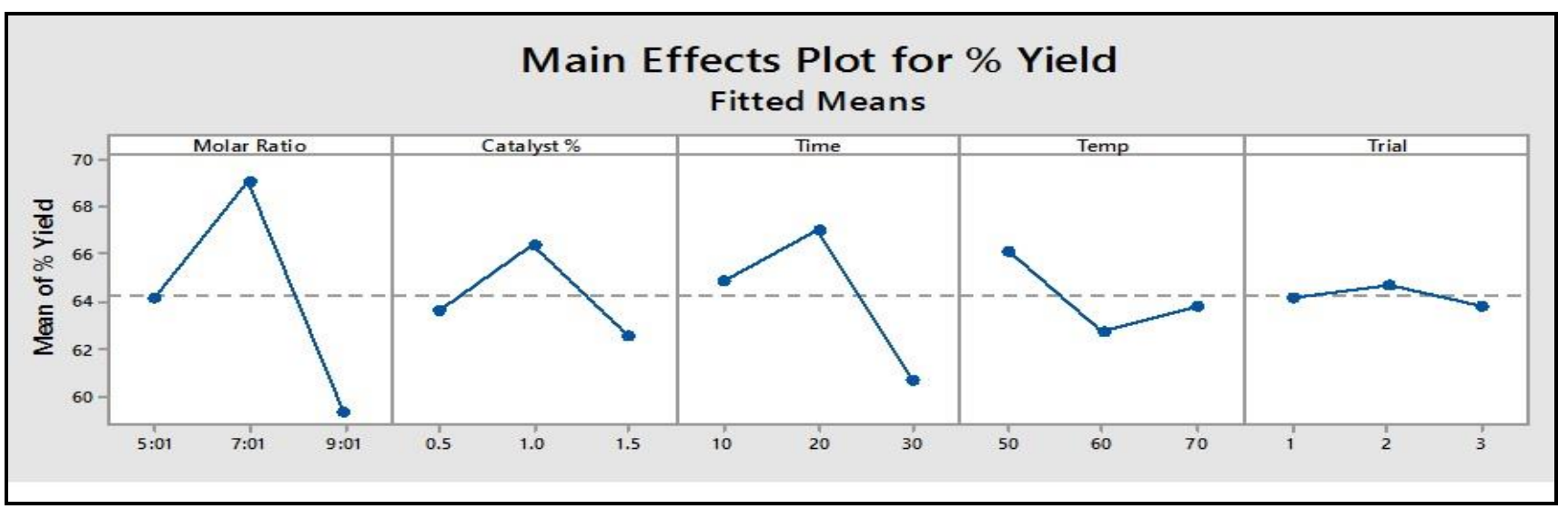

\section{Effect of alcohol to oil molar ratio:}

Among the four conditions chosen, liquor to crude oil molar proportion was found as the most huge parameter for trans-esterification [20]. The liquor to oil molar proportions 5:1, 7:1, 9:1 were coded as 1,2

and 3. Results show the best return (69\%) for the liquor to oil molar proportion as $7: 1$. This most

extreme worth is very well above mean yield an incentive as appeared in fig. 5 Optimum liquor to oil molar proportion is subsequently 7:1. Purpose behind this might be the immersed conditions to synthetic action with the crude WCO along these

lines giving most extreme conceivable change of the oil into the biodiesel. For the proportion relating to the main level, the yield is almost about the mean worth while the apportion comparing to the third level has the yield dropped extensively beneath the mean worth. This may be because of abundance of liquor accessible that prompts weakening of response blend subsequently bringing down the yield of the oil. Accordingly the ideal estimation of liquor to oil molar proportion is $7: 1$ [16].

\section{Effect of catalyst concentration:}

The measure of impetus utilized in the process is another variable to consider, on the grounds that it decides the response rate. Impetus focus was found as the third most critical procedure parameter [6]. Potassium hydroxide $(\mathrm{KOH})$ was chosen as an impetus in light of the fact that the base basic impetus gives a high Biodiesel yield in a short response time and the response can be done in straightforward hardware [8]. The impact of Potassium hydroxide sum on WCO mean rate yield is displayed in Fig. 5. Impetus fixation was takes as $0.5,1$, and 1.5 grams coded as 1,2 , and 3 individually were examined. Results demonstrate that most extreme yield $(66.5 \%)$ is for 1 gram of impetus fixation. For the other two levels in particular 1 and 3 , the yield is seen as altogether lower than the mean estimation of the yield. The primary degree of impetus focus gives the lower yield. This may be because of deficiency of the impetus fixation important for ester transformation. In any case, the third level additionally gives still lower yield. This may be because of the explanation that the additional impetus fixation supports the arrangement of glycerol as opposed to the biodiesel for example ester. So the greatest yield of about $66.5 \%$ is acquired at the second level for example $1 \%$ impetus focus [16].

\section{Effect of Reaction time:}

Response time of 10, 20, and 30 minutes was considered and coded as 1, 2 and 3 separately. To accomplish adequate contact between the reagents and the oil during response, they should be mixed well at consistent rate and all around combined [20]. For 10 minutes of response time, yield created was nearer to the mean yield esteem and for 30 minutes of response time, yield delivered was underneath mean yield esteem. Figure 5 shows that the greatest yield (67\%) was acquired for response time of 20 minutes. The yield acquired for the principal level is just somewhat over the mean worth while if there should arise an occurrence of the third level, the yield is extensively dropped to $60.25 \%$. This may be because of the explanation that the span past 20 minutes is the additional time coming about into more glycerol development bringing about the drop of biodiesel yield. So the ideal time of trans-esterification is 20 minutes that yields the most noteworthy for example $67 \%$ of biodiesel [16].

\section{Effect of Reaction temperature:}

The impact of response temperature on mean yield rate is appeared in Fig. 5. Depending on the oil used, trans-esterification can occur at different temperatures. The maximum yield percentage was obtained at $50^{\circ} \mathrm{C}$ temperature. 
It is seen that at the first level i.e. at $50^{\circ} \mathrm{C}$, the biodiesel yield is considerably above mean value. With the increasing in temperature, yield gets dropped. This might be due to some hindrances for catalytic. Further at still increased temperature at third level i.e. at $70^{\circ} \mathrm{C}$, there is slight improvement in the yield but still it is lower than the mean value. Therefore the optimum reaction temperature is at the first level i.e. $50^{\circ} \mathrm{C}$ [16].

\section{B. Properties of WCO based biodiesel}

In this present work physical property and chemical properties were tested. Chemical property tested comprises of acid value, iodine number, water content (moisture content), cetane number etc. Also, physical property test comprises of viscosity, density, and calorific value, flash and fire point. Following table sheds light on comparative discussion on property of waste cooking oil biodiesel and standard diesel. It can be seen that, properties better and closer to standard diesel. Biodiesel was set up out of Waste Cooking Oil and the properties were examined [19].

1. The estimation of thickness of Waste Cooking Oil Biodiesel is 3.58 centipoise. This worth satisfies the ASTM guideline (ASTM PS 121).

2. $868 \mathrm{~kg} / \mathrm{m}^{3}$ is the estimation of thickness of Waste Cooking Oil Biodiesel got during thickness test which likewise fulfills ASTM standard (ASTM PS 121)

3. Squander Cooking Oil Biodiesel has a Flash purpose of $135^{\circ} \mathrm{C}$ and a fire purpose of $141^{\circ} \mathrm{C}$. Both this qualities fulfills ASTM standard.

4. Corrosive estimation of Waste Cooking Oil Biodiesel is $0.44 \mathrm{mgKOH} / \mathrm{g}$ and Water substance of Waste Cooking Oil Biodiesel is $320 \mathrm{mg} / \mathrm{kg}$ (ASTM PS 121)

5. Squander Cooking Oil Biodiesel has a saponification estimation of $117.81 \mathrm{mgKOH} / \mathrm{g}$.

6. Cetane number of Waste Cooking Oil Biodiesel is 52 which meets the ASTM PS 121 Standard.

7. Calorific estimation of Waste Cooking Oil Biodiesel is $37531 \mathrm{KJ} / \mathrm{kg}$.

Biodiesel created structure Waste Cooking Oil has comparable properties as some other biodiesel. The qualities for motor execution related properties like thickness and consistency are inside standard worth. Water content is likewise in run. This shows it can use in CI motors as a substitute fuel. Fuel security related properties, Acid worth and saponification estimation of Waste Cooking Oil Biodiesel is likewise inside the range. Hence it has great stockpiling strength. Higher glimmer point and fire point infers that it very well may be moved and took care of securely.

\section{Economics of the WCO based biodiesel: (Cost Analysis)}

1. Waste cooking Oil cost $(\mathrm{A})=10$ Rupees /litre

2. Energy cost for 1 Litre waste cooking oil (B)

Energy cost $=$ Electrical energy required $\operatorname{cost}$ per unit $=28.0$

Rupees

Where,

Electrical energy required $=4.0 \mathrm{kWh}$

Electrical energy cost $=7$ Rupees $/ \mathrm{kWh}$

3. Transport cost $(C)=2.0$ Rupees $/$ Litre

4. Total operating cost $(D)=6.0$ Rupees.
Variable operating cost $=$ Labour + Maintenance + Other Charges $=4.0$ Rupees

Where,

Labour Charges $=2$ Rupees /litre

Other Charges $=2$ Rupees /litre

Fixed operating cost $=$ Capital cost + other Charge $=2.0$ Rupees /litre

Where,

Capital cost applied per $\mathrm{kg}=1$ Rupees /litre

Other Fixed Charges $=1$ Rupees /litre

Total operating cost $=$ Fixed cost + Variable $\cos t=6.00$ Rupees.

5. Cost of by product (Glycerol) $(\mathrm{E})=4$ Rupees $/$ litre

6 . Total cost of waste cooking oil/Litre $=(A+B+C+D)-(E)$

= 41 Rupees / litre

7. Price of diesel fuel oil/ Litre $=60.27$ Rupees $/$ litre

Cost of diesel fuel is 60.27 Rupees/liter and cost of waste cooking oil is 41 Rupees/liter and this utilization of waste cooking oil additionally fills the need of waste administration which is one of the most significant difficulties to our general public and for our feasible advancement. The expense of waste cooking oil is $31.97 \%$ not as much as diesel fuel.

\section{CONCLUSION}

In this investigation, WCO based Biodiesel is created by utilizing trans-esterification process. It was upgraded utilizing Taguchi test plan. Utilizing ANOVA, the ideal estimations of every parameter are resolved. The outcomes show that exceptionally compelling parameters in the creation of WCO based Biodiesel are molar proportion of liquor to oil, \% Catalyst, response time and temperature. The liquor to oil proportion is the most noteworthy parameter among the all. The request for criticalness for different parameters is season of response, impetus fixation, and response temperature. From the outcomes, it is likewise seen that that \% yield changes from preliminary to preliminary. From the chart of fundamental impacts plot, the most elevated \% yields relate to 7:1 molar proportion, $1 \%$ impetus, 20 min time units, and $50^{\circ} \mathrm{C}$ as response temperature. The cooperative energy impact of every one of these parameters when utilized at their ideal levels, results into $75.18 \%$ biodiesel yield which is clearly the most noteworthy among every one of the runs. This approves the aftereffects of streamlining. The property estimations similar with the diesel fuel additionally uncover that the WCO based biodiesel got in our work is reasonable for mixing with the regular diesel. Such a development of utilizing biodiesel as an incomplete supplant will lead towards practical improvement.

\section{ACKNOWLEDGMENT}

This examination work was supported by organization and the board of Shivaji University Kolhapur. We owe our uncommon gratitude to the Department of Technology Board of Governors who enabled us to utilize the offices for this examination work. Our thanks are additionally because of the World Bank, the Indian NPIU and Maharashtra SPFU for subsidizing the Department of Technology through TEQIP that created required offices at the Chemical Technology and Energy Technology Divisions at the grounds. 


\section{REFERENCES}

1. Amin Talebian Kiakalaieh, Nor Aishah Saidina, Amin Hossein Mazaheri, "A review on novel processes of biodiesel production from waste cooking Oil”, Applied Energy, vol.104, 2013, (pp. 683-710). https://www.sciencedirect.com/science/article/pii/S030626191200866 5.

2. Singh Chamandeep, "Optimization of Process Parameters for Production of Linseed Bio-fuel and Performance Investigation of Diesel Engine Fuelled with Linseed Biodiesel" A Project Thesis, 2014,(pp.1-102).

http://tudr.thapar.edu:8080/jspui/bitstream/10266/3150/4/3150.pdf .

3. D.M. Pilar, B.Evaristo , J.L Franscisco , Martin .M, Optimization of alkali-catalyzed trans-esterification of brassica carinata oil for biodiesel production, Energy Fuels, vol.18, 2004, (pp.77-83). https://pubs.acs.org/doi/pdf/10.1021/ef0340110 .

4. Ebenaza Godson. T, Vinoth.E, "Biodiesel Production from Waste Cooking Oil", and International Journal of Students' Research in Technology \& Management, vol. 3, no.8, 2015 (pp. 448-450). http://www.giapjournals.com/index.php/ijsrtm/article/view/ijsrtm383.

5. Fangrui Ma, Milford A. Hanna, "Biodiesel production: a review", Bio-resource Technology, vol.70, no.1, 1999 , (pp.1-15). https://www.researchgate.net/publication/222454178_Biodiesel_Prod uction_A_Review.

6. Guoqing Guan, Katsuki Kusakabe, Yamasaki Satoko, “Tri-potassium phosphate as a solid catalyst for biodiesel production from waste cooking oil, Fuel Processing Technology" vol. 90, no.4, 2009, (pp. 520-524).

www.researchgate.net/publication/244238772_Tripotassium_phospha te_as_a_solid_catalyst_for_biodiesel_production_from_waste_cookin g_oil .

7. Hulya Karabas, "Application of the Taguchi Method for the Optimization of Effective Parameters on the Safflower Seed Oil Methyl Ester Production", International Journal of Green Energy, vol.11, no.9, 2014 , (pp. 1002-1012).

https://www.tandfonline.com/doi/abs/10.1080/15435075.2013.829475

8. Le Tu Thanh, Kenji Okitsu, Luu Van Boi and Yasuaki Maeda, "Catalytic Technologies for Biodiesel Fuel Production and Utilization of Glycerol: A Review”, Catalysts, vol. 2, no.1, 2012, (pp. 191-222). https://www.mdpi.com/2073-4344/2/1/191 .

9. Mangesh G. Kulkarni and Ajay K. Dalai, "Waste Cooking Oils an Economical Source for Biodiesel: A Review”, Ind. Eng. Chem. Res, vol. 45, no.9, 2006, (pp. 2901-2913) https://pubs.acs.org/doi/abs/10.1021/ie0510526 .

10. Mofijur M., Masjuki H.H., Kalam M.A., Atabani A.E., Shahabuddin M., Palash S.M., Hazrat M.A., "Effect of biodiesel from various feedstock's on combustion characteristics, engine durability and materials compatibility: A review", renewable and sustainable energy reviews, vol. 28, 2013, (pp. 441-455). https://www.sciencedirect.com/science/article/pii/S136403211300496 6.

11. Montgomery D. C., Peck E. A., and Vining, G. G ,Introduction to linear regression analysis, 3rd edition, John Wiley and Sons, 2006

12. Murugesan A., Umarani C., Subramanian R., Nedunchezhian N, "Bio-diesel as an alternative fuel for diesel engines - A review", Renewable and Sustainable Energy Review ,vol. 13, no.3, 2009, (pp. 653-662).

https://www.sciencedirect.com/science/article/pii/S136403210700143 8.

13. Nirmith Kumar Mishra, Mr. D Muppala., Mr. .P Bala Krishna, "PERFORMANCE AND ANALYSIS USING MAHUA SEED OIL", International Journal of Advanced Engineering and Global Technology, vol. $\quad 3, \quad$ no.7,2015. http://ijaegt.com/wp-content/uploads/2015/05/409532-966-975-nirmit h.pdf .

14. Nor Hazwani Abdullah, Sulaiman Haji Hasan, and Nurrul Rahmah Mohd Yusoff, "Biodiesel Production Based on Waste Cooking Oi (WCO)", International Journal of Materials Science and Engineering, vol. 1, no. 2, 2013, ( pp. 94-99).

http://www.ijmse.net/index.php?m=content\&c=index\&a=show\&catid $=32 \& i d=38$.

15. Patil P.D, Rao CR, Wasif, AI, Anekar SV, Nagla, JR., "Mass transfer enhancement through optimized extraction of a natural dye from Bougainvillea glabra juss. Bracts", vol. 5, no.4,2014. http://op.niscair.res.in/index.php/IJNPR/article/view/5305 .

16. Pravinkumar.D Patil, Aniruddha.S Joshi, Masoomraja.Z Mulla , D.M. Nangare, "Performance Studies of CI Engine Using WCO based Biodiesel Blend with Conventional Diesel", International Journal of Emerging Technology and Advanced Engineering ,vol.7, no.9,2017.

https://www.researchgate.net/publication/319980694_Performance St udies_of_CI_Engine_Using_WCO_based_Biodiesel_Blend_with_Co nventional_Diesel.

17. R. Sathish, K. Sureshkumar and R. Velraj,"optimization of biodiesel production from Manilkara zapota (L.) Seed oil using Taguch method", Fuel, vol.140, 2015, (pp. 90-96) https://www.sciencedirect.com/science/article/pii/S001623611400972 7 .

18. Sivasamy A., K. Y. Cheah, Fornasiero P., Zinoviev F.S., and Miertus S., "Catalytic applications in the production of biodiesel from vegetable oils," ChemSusChem, vol. 2, no. 4, 2009 ,(pp.278-300). https://www.ncbi.nlm.nih.gov/pubmed/19360707

19. Swaroop. C, Tennison K. Jose, A Ramesh ,"Property Testing Of Biodiesel Derived From Coconut Testa Oil and Its Property Comparison With Standard Values", vol. 2, no. 2,2016. http://troindia.in/journal/ijapme/vol2iss2/37-41.pdf

20. Xiangmei Meng, Guanyi Chen, Yonghong Wang, "Biodiesel production from waste cooking oil via alkali catalyst and its engine test”, Fuel Processing Technology, vol. 89, no.9, 2008, (pp. 851-857)

21. https://www.researchgate.net/publication/222553333_Biodiesel_Prod uction_From_Waste_Cooking_Oil_via_Alkali_Catalyst_and_its_Engi ne_Test .

22. Zhang Y., Dube M.A., McLean D.D., Kates M., "Biodiesel production from waste cooking oil: Process design and technological assessment", Bioresource Technology, vol. 89, no.1, 2003 ( pp. 1-16) https://www.ncbi.nlm.nih.gov/pubmed/12676496

23. ZHU Huaping, WU Zongbin, CHEN Yuanxiong, ZHANG Ping, DUAN Shijie, LIU Xiaohual, MAO Zongqiang "Preparation of Biodiesel Catalyzed by Solid Super Base of Calcium Oxide and Its Refining Process", CHINESE JOURNAL OF CATALYSIS, vol. 27, no. 5, 2006, (pp.391-396), https://www.sciencedirect.com/science/article/pii/S1872206706600247

\section{AUTHORS PROFILE}

Author Name : Dr. Pravinkumar D. Patil

Designation/ Scholar/Student: Assistant Professor

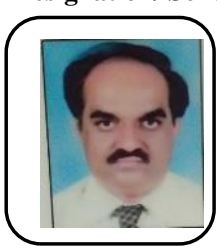

Department Name : Chemical Technology

Institute Name :Department of Technology,

Shivaji University

City Name : Kolhapur

Country Name : India

\section{Qualification :}

- B.E. ( Chemical Engineering)

- M.E ( Chemical Engineering)

- Ph.D. ( Chemical Engineering)

Research Interest :

- Green Chemistry,

- Natural Products Development

- Energy and Environment Conservation in Chemical Industry

Ongoing Project:

Refining of Tyre Waste Oil, Cavitation Phenomenon for Waste Water Treatment, Extraction of Natural Dyes for Textile Application, Increasing Crop Yield using magnetically treated water for irrigation.

\section{Author Name : Mr. Aditya M. Buradkar Designation/ Scholar/Student:}

Student

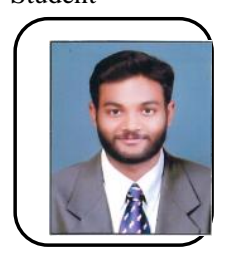

Department Name : Faculty of Process and systems Engineering

Institute Name : Otto-Von-Guericke University City Name : Magdeburg Country Name : Germany

Qualification :

- M.S. ( Chemical and Energy Engineering) Pursuing

- B.Tech. Chemical Engineering (2018)

- Diploma in Industrial Safety Health and Environment (2018)

Published By:

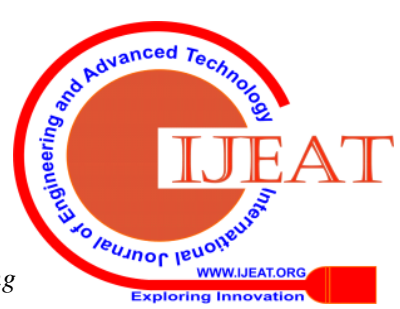


Taguchi Optimization for Waste Cooking Oil Based Biodiesel Preparation

Research Interest :

- Polymer Chemistry,

- Ctalysis and reactions

- Industrial Safety

Paper Publications:

[1] Review on Extraction of Biodiesel from Waste Cooking Oil using Ultra-Sonication

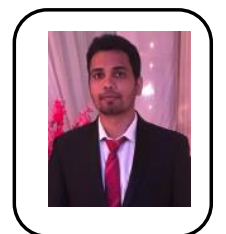

Author Name : Mr. Masoomraja Zakir Mulla

Designation/ Scholar/Student: Student

Department Name : Energy Technology

Institute Name :Department of Technology, Shivaji

University

City Name : Kolhapur

\section{Country Name : India}

Qualification :

- B.E. ( Chemical Engineering) 2015

- M.Tech. ( Energy Technology ) 2018

- $\mathrm{NEBOSH}$

Research Interest :

- Renewable energy

- Industrial Safety

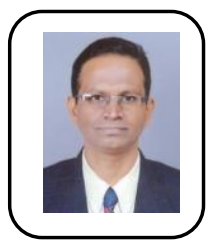

Author Name : Mr. P.A.Prabhu

Designation/ Scholar/Student: Assistant Professor

Department Name : Mechanical Engineering

Institute Name :Department of Technology, Shivaj

University

City Name : Kolhapur

Country Name : India

Qualification :

- $\quad$ B.E. ( Mechanical Engineering) 1993

- $\quad$ M.Tech. ( Energy Technology ) 2014

Subjects:

- $\quad$ Ph.D. ( Mechanical Engineering ) pursuing

- Nanotechnology

- Energy Engineering

- Control System

- Machine Drawing

- Engineering Graphics

- Basic Mechanical Engineering

Research Interest

- Renewable energy

- Solar thermal energy storage system

- Phase change materials

- 3D printing technology

Paper Publications:

[1] Review of Phase Change Materials for Thermal Energy Storage Applications

[2] Characterization of PCM Material-Sodium Sulphate Decahydrate (Glauber's salt) for Low Pressure Temperature solar thermal energy storage system. Funding received from TEQIP-II for Design, Development and Evaluation of Solar Thermal Energy Storage System Using PCM Material-Sodium Sulphate Decahydrate (Glauber's salt)

\section{Ongoing Project :}

Design, Development and Evaluation of Solar Thermal Energy Storage System for low temperature applications.

\section{$\underline{\text { Citations }}$}

h-index

$\underline{\text { i10-index }}$

Author Name : Prof. J. R. Nagla

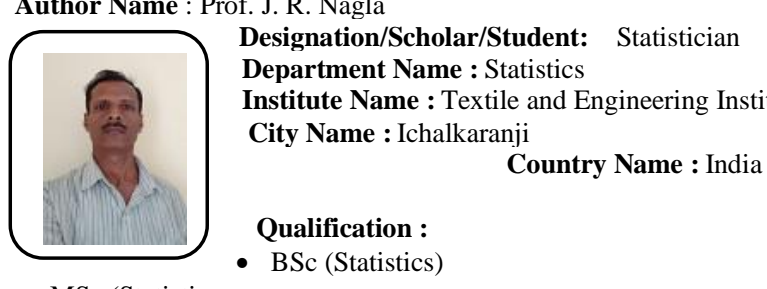

- MSc (Statistics

Subject:

- Statistical analysis expertise using computer softwares

Research Interest :

- Statistics

Paper Publications:

[1]The book Statistics for Textile Engineers' was published by woodhead publishing india pvt. Ltd. in 2014. 